\title{
Reviewing the benefits and challenges of overseas practice: Reflections upon coming home
}

Liz Beddoe and Allen Bartley, University of Auckland, New Zealand

\begin{abstract}
INTRODUCTION: Given the diversity of practice and understanding of social work across the globe and its distinctive shape in specific national settings, practitioners working in a new country encounter different community, professional and workplace cultures which may pose challenges. This current study contributes to a larger programme of work undertaken to address the transnational nature of the social work profession in Aotearoa New Zealand and elsewhere.
\end{abstract}

METHOD: The study aim was to explore the experiences of Aotearoa New Zealand qualified social workers who have practised in another country and have returned home. Participants in an online survey were recruited via an invitation to all members of the Aotearoa New Zealand Association of Social Workers. The questionnaire was designed to obtain broad data about the experiences of social workers in their overseas employment and perceptions on their return home.

FINDINGS: Many participants had layers of transnational experience having practised as social workers in multiple countries. Participants reported overall satisfaction with overseas experiences which had provided professional opportunities for learning and development, and better pay and conditions. Coming home presented new challenges and interesting perceptions of social work in Aotearoa.

IMPLICATIONS: Adjustment to new practice locations and, as shown in this small exploratory study, returning "home" can be disruptive to professional perspectives. While overseas practice is enriching, it carries with it both relocation benefits and costs, confirming earlier research. Better employer recognition of the challenges of returning social workers, and the enhanced skills they bring home may offset any dislocation experienced.

KEYWORDS: transnational social workers; global workforce mobility; Aotearoa New Zealand social work; practice

AOTEAROA

NEW ZEALAND SOCIAL WORK 31(1), 72-88.

CORRESPONDENCE TO: Allen Bartley,

a.bartley@auckland.ac.nz
With growing global workforce mobility, it can be expected that a large percentage of professionals will practise in a country other than where they obtained their professional qualification. In fact, social work has been amongst the professions targeted in changes to migration policies designed to overcome labour shortages (Hussein, Manthorpe,
\& Stevens, (2011; Zanca \& Misca, 2016). In Aotearoa New Zealand, nearly $10 \%$ of the registered social work workforce were professionally qualified overseas (Bartley et al., 2011). This raises questions about how we strengthen the social and cultural wellbeing of migrating social workers to ensure resilience in practice. Gathering information 
on the experiences of transnational social workers at all points in their professional journeys will help to inform those strategies.

A social worker mobility research team based at the University of Auckland has conducted prior mixed methods studies of the overseas qualified workforce in Aotearoa New Zealand (Bartley, Beddoe, Fouché, \& Harington, 2012), experiences of migrant social workers in Aotearoa New Zealand (Bartley \& Beddoe, 2018; Bartley et al., 2011; Fouché, Beddoe, Bartley, \& de Haan, 2013; Fouché, Bartley, Beddoe, \& Brenton, 2013; Fouché, Beddoe, Bartley, \& Parkes, 2015) and a small qualitative study of Aotearoa New Zealand social workers currently practising in the United Kingdom (UK) and Ireland (Beddoe \& Fouché, 2014). Findings of the previous research have concluded that practising social work in a new context creates challenges and opportunities. Given the breadth of approaches and models of employment in social work across the globe and its accordingly distinctive shape in specific national settings, many elements of professional practice - for example supervision, pre- and post-qualifying education - are likely to be very different across these diverse contexts (Bartley et al., 2011; Beddoe et al., 2011).

Our research question was: What are the views of New Zealanders who have returned home to practise as they reflect on their professional overseas experiences and any positive or negative experiences of coming home? Our aim was to explore, via an anonymous online survey, the experiences of a larger group of Aotearoa New Zealandqualified social workers who have practised in overseas jurisdictions and have since returned to practise at home. This group would offer useful reflections on professional mobility in social work.

\section{Literature}

There is now an extensive literature on the increasing mobility of social workers in
Aotearoa New Zealand, as noted earlier, and in the United Kingdom (Hanna \& Lyons, 2014; Hatzidimitriadou \& Psoinos, 2017; Hussein, 2014; Hussein et al., 2011; Moriarty, Hussein, Manthorpe, \& Stevens, 2012; Tinarwo, 2015; Zanca \& Misca, 2016); Ireland (Walsh, Wilson, \& O'Connor, 2010); Australia (Harrison, 2013; Papadopoulos, 2017 2018; Zubrzycki, Thomson, \& Trevithick, 2008; Modderman, Threlkeld, \& McPherson, 2017); Canada (Brown, Sansfaçon, Éthier, \& Fulton, 2014; Fulton, Pullen Sansfaçon, Brown, Éthier, \& Graham, 2016; Pullen Sansfaçon, Brown, Graham, \& Dumais Michaud, 2013). More recently, research has been published that has reported on the experiences of migrant workers in the United States (Lin, Chiang, Lux, \& Lin, 2018), Zimbabwean social workers in South Africa (Mangena \& Warria, 2017) and of Latin American social workers in Switzerland (Bolzman, 2015).

There are several commonly occurring challenges reported by transnational social workers, reported in our own research and in other jurisdictions (see Bartley \& Beddoe, 2018 for a range of reports). First, many have experienced a degree of professional dislocation and discrimination (Fouché, Beddoe, Bartley, de Haan, 2013; Fouché, Beddoe, Bartley, \& Parkes 2013; Hatzidimitriadou \& Psoinos, 2017), sometimes to the extent that they face challenges in finding meaningful employment commensurate with their skills. Secondly, they may find gaining registration or licensing involves them in protracted communications over the recognition of their professional qualifications (Fouché, Beddoe, Bartley, de Haan, 2013; Fouché, Beddoe, Bartley, \& Parkes 2013; Brown et al., 2014; Fulton et al., 2016; Papadopoulos, 2017, 2018). Thirdly, they too, often experience a very limited programme of transition (induction) in their new professional contexts, in comparison to those offered to members of other professions (Brown et al., 2014; Peter, Bartley, \& Beddoe, 2017). Lastly, transnational social workers must negotiate - 
in both their private and professional lives the complexity of the new socio-cultural and political environment.

While social work is practised in many countries, each has its own unique community, professional and workplace culture, and is embedded in its particular socio-cultural, political and historical contexts. In the Aotearoa New Zealand context, social work is underpinned by obligations to the Treaty of Waitangi, the founding document, an aspect not always understood by incoming transnational social workers. Walsh-Tapiata, Simmons, MeoSewabu, and Umugwaneza (2018) argue that responsible hosts must offer a process of cultural encounter to assist transnational social workers to be better integrated into their new country, their communities and their professional practice. Because of the significance of the Treaty of Waitangi, social workers are very attuned to recognising the centrality of culture in social work relationships. Significant differences pose challenges to in- and out-bound migrant social workers as noted by UK-based social workers in Beddoe and Fouché (2014) where participants acknowledged that they had cross-cultural skills but these needed examination and adjustment in a new cultural context, reflecting a conscious need to learn about very different cultural groups.

While transnational social work is a growing field of study there is a gap in research exploring the experiences of social workers returning back to practise in the country where they qualified and, in particular, in Aotearoa New Zealand. We knew from our study in the UK and Ireland (Beddoe \& Fouché, 2014) that New Zealanders have joined the many social workers around the world who have decided to travel overseas and work for a period. Some were included in recruitment schemes to bring social workers to the United Kingdom and Ireland during the 2000s (Beddoe \& Fouché, 2014; Moriarty et al., 2012; Walsh et al., 2010) and others following the long-held tradition of seeking to expand personal horizons with overseas travel. Recent impacts of social worker shortages and globalisation have led to "OE" not just being an experience undertaken by young graduates but also by more mature professionals.

Aotearoa New Zealand social workers who had practised overseas and returned home were a group not previously studied by the research team. This article reports on a small exploratory study in which returning New Zealand social worker reflected on their overseas practice experience and their return home.

\section{Method}

The study recruited participants to an anonymous online survey via an e-mail invitation to all members of the Aotearoa New Zealand Association of Social Workers (ANZASW). The survey questions included a mixture of open, closed and Likert-type response questions, focused that focused on participants' reflections apposite to the research question. The study gained ethical approval from the University of Auckland Human Participants Ethics Committee. The online questionnaire was available for 16 weeks during 2014.

In addition to demographic information, the survey addressed three major topic areas: overseas experience (motives for emigration; destinations; professional roles; experiences of induction; reflections on professional differences); return to Aotearoa New Zealand (motivation; employment; job satisfaction; reflection on professional differences), and, overall reflection/ assessment of transnational experience. This article focuses primarily on participants' reflections of their overseas experience, and only briefly touches on their reflections of returning home near the end of our discussion. The questionnaire was designed to obtain broad quantitative data about the experiences and perceptions of the target group of social workers. The survey also provided an important opportunity for 
participants to provide more detail about their particular experiences. Space was thus provided to obtain more detail via additional open questions. Ballou (2008) notes that open-ended questions in a survey, while demanding more cognitive effort by participants, offer many benefits to researchers. A significant benefit is that open questions enable survey participants to explain their answer to a prior question, deepening our understanding of the phenomenon.

\section{Analysis}

A total of 58 social workers began the survey; however, 10 completed only the basic demographic questions and withdrew before completion. Thus, the data from the 48 respondents who completed the survey are what we report on here. We cannot comment on how representative this is as it is unknown how many social workers in Aotearoa New Zealand are actually in the target population (i.e., having qualified in Aotearoa New Zealand, gained practice experience overseas, and returned).

Descriptive analysis was conducted using SPSS. The open question responses, albeit mainly brief, did produce surprisingly rich data. A simple textual analysis was conducted, with initial codes generated by line-by-line coding, followed by the generation of broader themes identified by independent reading of the reports by the two authors.

\section{Findings}

\section{Survey findings}

The demographic profile of the survey participants is provided in Table 1.

Participants were asked about their highest educational attainment: they held a diverse range of qualifications, from sub-degree diplomas in social work or social practice $(n$ $=9$, or $19 \%$ ) to doctorate degrees in social work $(n=2)$. A third of participants held a BSW, with several more holding a qualifying master's degree. Ten participants (21\%) held postgraduate diplomas; most of these were in social work or related disciplines (e.g., counselling, social service supervision, etc.). A total of five participants (10\%) indicated that their highest qualifications were in disciplines not directly related to social work (e.g., history, German, anthropology). Most of these qualifications were Aotearoa New Zealand-based: only five of the 48 participants $(10 \%)$ had gained their highest (non-qualifying) qualifications overseas.

Table 1. Survey Participants

\begin{tabular}{|c|c|c|}
\hline Gender $(N=48)$ & $N$ & $\%$ \\
\hline Female & 43 & 89.6 \\
\hline Male & 5 & 10.4 \\
\hline \multicolumn{3}{|l|}{ Age $(N=48)$} \\
\hline $21-30$ & 7 & 14.6 \\
\hline $31-40$ & 7 & 14.6 \\
\hline $41-50$ & 14 & 29.2 \\
\hline $51-60$ & 14 & 29.2 \\
\hline $61+$ & 6 & 12.5 \\
\hline \multicolumn{3}{|l|}{$\begin{array}{l}\text { Country of Highest } \\
\text { Qualification }(N=48)\end{array}$} \\
\hline New Zealand & 43 & 89.6 \\
\hline South Africa & 2 & 4.2 \\
\hline England & 1 & 2.1 \\
\hline Australia & 1 & 2.1 \\
\hline USA & 1 & 1.7 \\
\hline
\end{tabular}

For a majority of participants (58\%), England represented their first overseas practice destination, the most popular amongst participants: a third of them (the largest group) had practised in both Aotearoa New Zealand and England. Most of the participants had layers of transnational experience, having practised as social workers in multiple countries. A total of 30 of the 48 respondents indicated that they had practised in two countries (for all but one respondent, this was Aotearoa New Zealand plus one other); however, 13 participants (19\%) had practised in three 


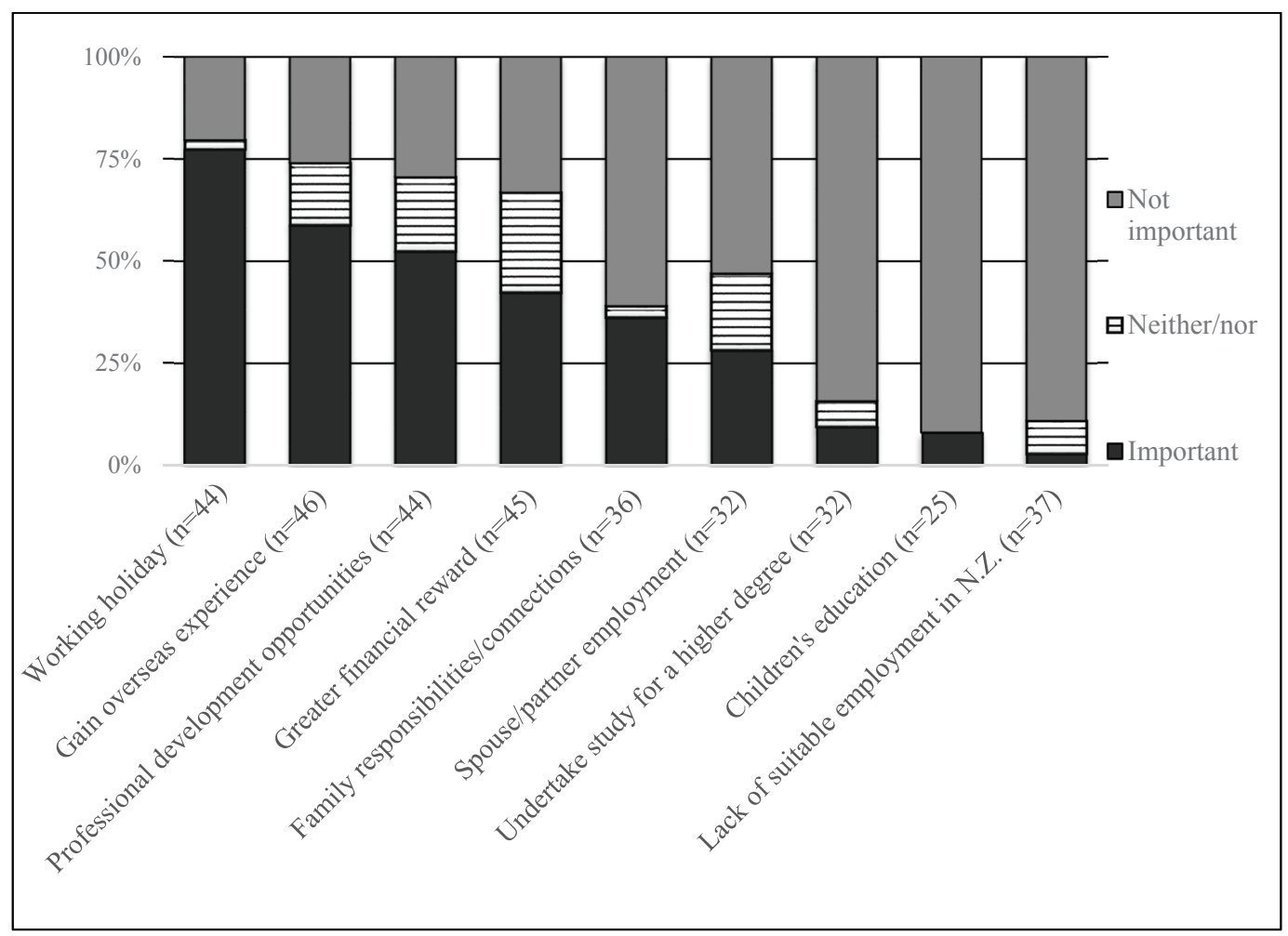

Figure 1. Considerations when participants decided to leave Aotearoa New Zealand.

or more different countries, including three participants who had worked as social workers in four or more different jurisdictions. One had practised in Aotearoa New Zealand, England, Wales, Northern Ireland, and the Republic of Ireland. In total, two-thirds $(65 \%)$ of participants had practice experience in the UK.

It was important to note that reflecting on "coming home" includes making comparisons about what was experienced in the "away" country. Participants were asked to consider the factors that had motivated them to leave in the first place, and to rate the relative importance of nine different factors, shown in Figure 1. More than threequarters of participants rated a working holiday as important - this was the most highly rated factor in the survey. More than half also rated as important considerations the desire to gain overseas experience and professional development opportunities. The least important factors were: to undertake study for a higher degree (9\%); for children's education ( $8 \%$ ); and a lack of suitable employment in New Zealand (3\%).

Finding suitable work was noted as a challenge in previous research for incoming transnational social workers (Fouché, Beddoe, Bartley, \& Brenton, 2013; Papadopoulos, 2016) but this was not the experience of our outbound New Zealand social workers. Table 2 shows that most participants in this study found their first social work job in an overseas context within three months, and all had found social work employment by six months. Immediate employment is generally an indication that they were relocated with the assistance of an agency or recruiting arm of their new employer. It is also in line with most participants' aspirations when they departed Aotearoa New Zealand i.e., to build their careers. 
Table 2. Countries Employed in and Time to Gain First Job

\begin{tabular}{|c|c|c|c|}
\hline \multicolumn{2}{|c|}{ First country (outside NZ) in which you practised social work $(n=48)$} & $N$ & $\%$ \\
\hline & England & 27 & 56.3 \\
\hline & Australia & 12 & 25.0 \\
\hline & Scotland & 3 & 6.3 \\
\hline & Republic of Ireland & 2 & 4.2 \\
\hline & Fiji & 1 & 2.1 \\
\hline & Canada & 1 & 2.1 \\
\hline & USA & 1 & 2.1 \\
\hline & South Africa & 1 & 2.1 \\
\hline \multicolumn{4}{|c|}{ How long did it take you to find social work employment in the FIRST overseas country? $(N=46)$} \\
\hline & Immediately & 33 & 71.7 \\
\hline & Less than 3 months & 11 & 23.9 \\
\hline & 4-6 months & 2 & 4.3 \\
\hline \multicolumn{4}{|c|}{ All countries in which you practised as a social worker $(N=48)$} \\
\hline \multicolumn{4}{|l|}{1 country only $(n=5)$} \\
\hline & Australia only & 3 & 6.3 \\
\hline & England only & 2 & 4.2 \\
\hline \multicolumn{4}{|l|}{2 countries $(n=30$} \\
\hline & $\mathrm{NZ}+$ England & 16 & 35.4 \\
\hline & $\mathrm{NZ}+$ Australia & 7 & 14.6 \\
\hline & $\mathrm{NZ}+$ Republic of Ireland & 2 & 4.2 \\
\hline & $\mathrm{NZ}+$ Scotland & 1 & 2.1 \\
\hline & $\mathrm{NZ}+$ South Africa & 1 & 2.1 \\
\hline & $\mathrm{NZ}+\mathrm{USA}$ & 1 & 2.1 \\
\hline & $\mathrm{NZ}+$ Other & 1 & 2.1 \\
\hline \multicolumn{4}{|l|}{3 countries $(n=10)$} \\
\hline & $\mathrm{NZ}+$ England + Scotland & 3 & 6.3 \\
\hline & $\mathrm{NZ}+$ Australia + England & 2 & 4.2 \\
\hline & $\mathrm{NZ}+$ England + Other & 1 & 2.1 \\
\hline & $\mathrm{NZ}+$ England + Canada & 2 & 4.2 \\
\hline & $\mathrm{NZ}+$ England + Republic of Ireland & 1 & 2.1 \\
\hline & $\mathrm{NZ}+$ China + USA & 1 & 2.1 \\
\hline \multicolumn{4}{|l|}{$4+$ countries $(n=3)$} \\
\hline & $\mathrm{NZ}+$ England + Wales + Northern Ireland + Republic of Ireland & 1 & 2.1 \\
\hline & $\mathrm{NZ}+$ Australia + England + South Africa & 1 & 2.1 \\
\hline & $\mathrm{NZ}+$ Australia + England + Wales & 1 & 2.1 \\
\hline
\end{tabular}




\begin{tabular}{|c|c|c|}
\hline \multicolumn{3}{|c|}{ Country of MOST RECENT overseas social work practice $(N=48)$} \\
\hline England & 26 & 54.2 \\
\hline Australia & 12 & 25.0 \\
\hline Scotland & 3 & 6.3 \\
\hline Republic of Ireland & 3 & 6.3 \\
\hline Other & 2 & 4.2 \\
\hline USA & 1 & 2.1 \\
\hline South Africa & 1 & 2.1 \\
\hline
\end{tabular}

Table 3 illustrates how popular England was as a destination for the survey participants. Nearly two-thirds of all participants (62.5\%) had practised in England. The total of $220.8 \%$ of cases indicates that, on average, each participant had nominated at least two jurisdictions. It is noteworthy that not all the participants had practised in New Zealand: five of the 48 participants gave no indication that they had ever practised in the place they called home. As the survey instrument did not ask for explanations in such cases, we do not know their specific stories. Their reflections on overseas practice are valuable; however, we have not included responses (when they were offered) about comparisons between New Zealand and overseas practices.

Participants were asked how long they had lived or practised social work overseas, and fully two-thirds had practised overseas for

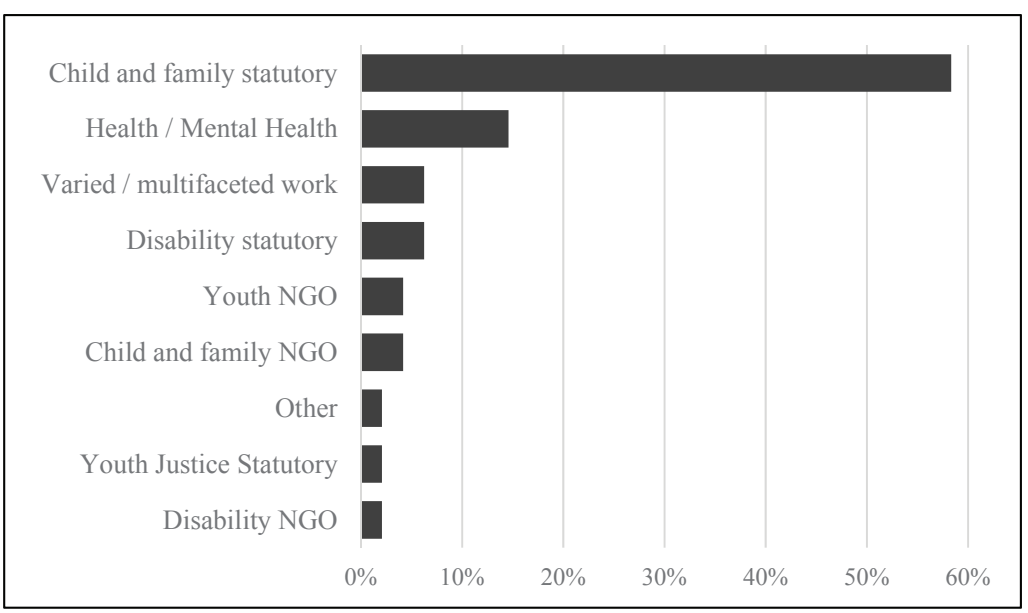

Figure 2. Primary field of overseas practice $(n=48)$. five years or less; three had been in overseas practice for $20+$ years. Most had spent at least some of their time overseas not working as social workers. Most (81\%) indicated that they had worked primarily in statutory roles whilst overseas, and the majority of these were in children's services (see Figure $2)$. Seven participants (15\%) indicated their primary field of overseas practice was in health or mental health.

Nearly two-thirds of participants $(N=48)$ indicated that they had received some induction or training at their first overseas social work position, while just over a

Table 3. Total of Jurisdictions in which Participants Practised $(\mathrm{N}=48)$

\begin{tabular}{|l|c|c|c|}
\hline \multirow{2}{*}{ New Zealand } & \multicolumn{2}{|c|}{ Responses } & \multirow{2}{*}{$\begin{array}{c}\text { Percent of } \\
\text { Cases }\end{array}$} \\
\cline { 2 - 4 } & N & Percent & \\
\hline England & 42 & $39.6 \%$ & $87.5 \%$ \\
\hline Australia & 30 & $28.3 \%$ & $62.5 \%$ \\
\hline Wales & 14 & $13.2 \%$ & $29.2 \%$ \\
\hline Republic of Ireland & 4 & $5.7 \%$ & $12.5 \%$ \\
\hline Canada & 2 & $1.9 \%$ & $4.2 \%$ \\
\hline USA & 2 & $1.9 \%$ & $4.2 \%$ \\
\hline South Africa & 2 & $1.9 \%$ & $4.2 \%$ \\
\hline Other (unspecified) & 2 & $1.9 \%$ & $4.2 \%$ \\
\hline China & 1 & $.9 \%$ & $2.1 \%$ \\
\hline Northern Ireland & 1 & $.9 \%$ & $2.1 \%$ \\
\hline Total responses & 106 & $100.0 \%$ & $220.8 \%$ \\
\hline
\end{tabular}


third indicated that they had not received any induction/training. Of those 31 who had received induction or training at their first overseas social work position, only 9 $(19 \%)$ indicated that their induction had prepared them pretty well or very well to practise social work in the new context. Just over $40 \%$ indicated that their induction/ training prepared them a little bit or was adequate (see Table 4). Specific responses about particularly helpful elements of their induction in those overseas contexts included those which focused on legislation, on clinical/practice skills and on processes and the policy context. Other responses included activities like on-the-job training, supervision and spending a period of time shadowing an experienced local social worker. There were no discernible patterns in the data relative to the relationship between the provision of induction and the country in which the respondent had gained their first overseas social work position. The idiosyncratic

Table 4. Aspects of Induction Training

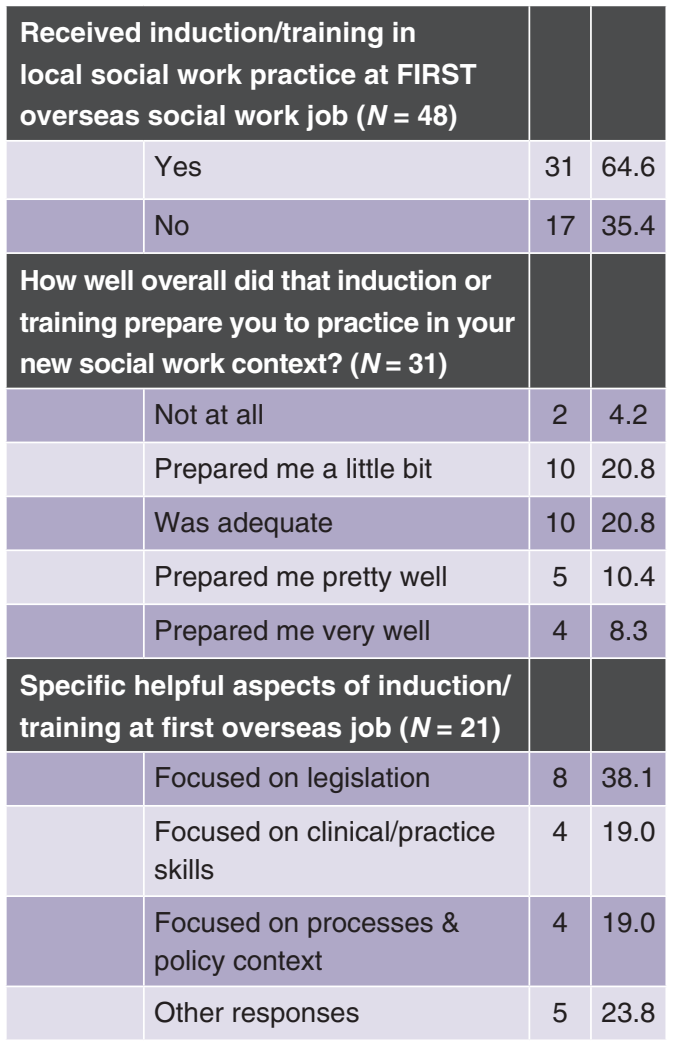

nature of induction for transnational social workers reflects the reality that employers alone - without reference to, or input from, the relevant professional bodies - determine what induction, if any, is provided, as noted in our literature review (Peter et al., 2017) in which induction of three professions: teaching, nursing and social work were compared.

The participants were asked about whether there were aspects of the induction training that proved especially helpful to their practice. A majority of $56.3 \%$ did not find useful aspects, with $43.8 \%$ responding positively. In response to an open question, participants positively mentioned information imparted on legislation and court-related skills, specific clinical or practice skills, counselling skills, and reflective practice and supervision. Only one person reported training or orientation on the cultural and historical considerations in relation to the indigenous and migrant populations: this respondent gained this training while working in Australia.

Participants were asked to offer an overall assessment of their satisfaction with their overseas social work experience, with a specific focus on four different domains: personal and social enjoyment; professional experience; professional development; and professional networks. Participants were generally very positive about their experiences. Their responses for each question were based on a five-point ordinal scale, with the end-points of the scale labelled Not at all satisfactory and Completely satisfactory; the other points on the scale were labelled merely with numbers, 2, 3, and 4 .

Participants rated their overseas experience as being highly satisfactory overall (Figure 3). Responses rated the personal and social enjoyment domain most satisfactory in fact, the median response was the Completely satisfactory response with $58 \%$ of the participants indicating that level of satisfaction. The median response for each of the other domains was the point just below 


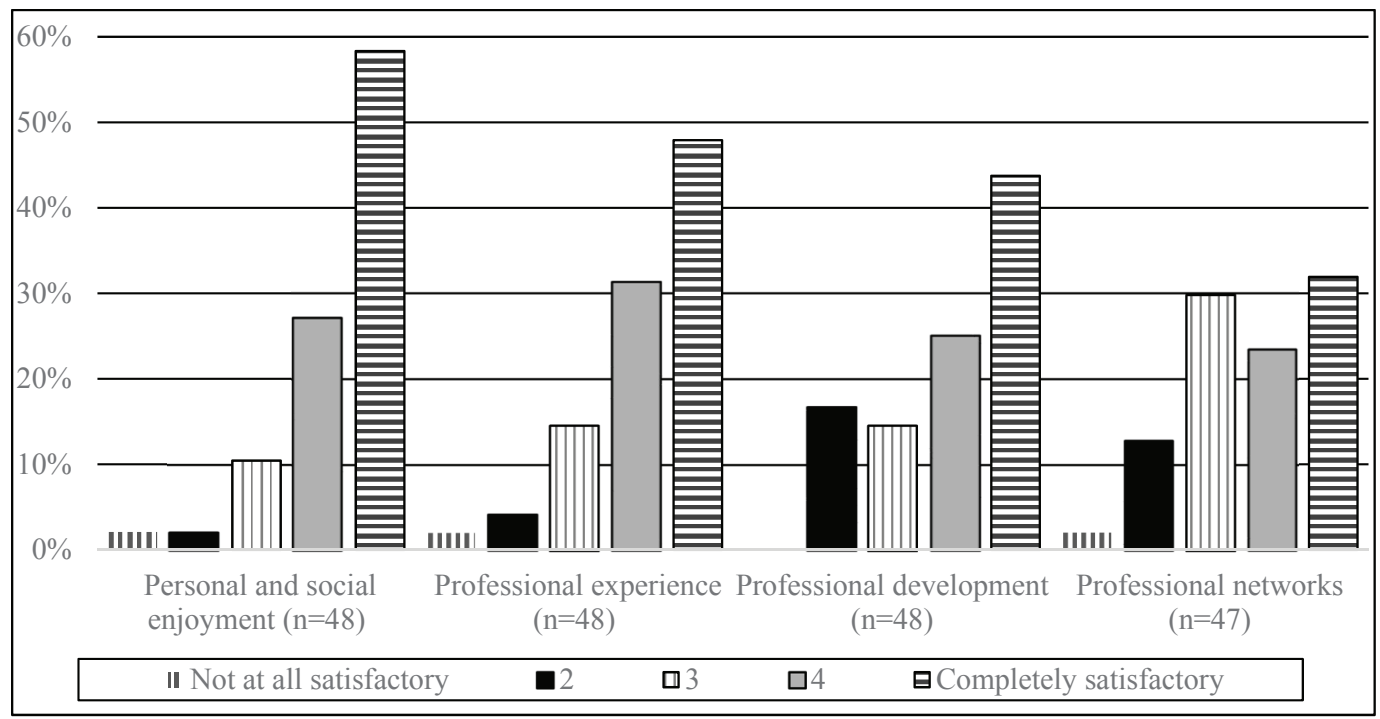

Figure 3. Overall satisfaction with overseas social work experience.

Completely satisfactory - the score of 4 on the 5 -point scale. However, the contours of the responses for each of the remaining domains varied. Nearly half of the participants rated their professional experience as being Completely satisfactory, $10 \%$ fewer than for personal and social enjoyment, though the Unsatisfactory responses were still very low. In fact, across all four of the domains, no more than $2 \%$ of the responses indicated a Not at all satisfactory assessment, and there were no such responses for the professional development domain, despite a larger proportion of the sample moving towards the ambivalent and negative end of the scale. Least positively assessed was the domain of professional networks: though the median score was still 4 out of 5 , there were fewer Completely satisfactory responses, and more ambivalent responses than in any of the other domains.

The survey asked participants to consider six different elements of social work practice that can be challenging in unfamiliar cultural and professional contexts. These different elements include: language; the status of social work; cultural differences; professional issues; the nature of professional practice; and the work culture of specific workplaces (see Figure 4). Similar to the Satisfaction scale above, responses were mapped on a fivepoint ordinal scale in which only the extreme responses were labelled; this time with Not at all challenging and Completely challenging as points 1 and 5 respectively. The interior points on the scale were labelled simply with numbers from 2 to 4 . Surprisingly - especially given the earlier responses regarding induction - most of the responses to each of the elements tended away from the Completely challenging end of the scale. The median response to the element of "Language" was Not at all challenging. This perhaps reflects the prominence of Anglophone destinations amongst most of the participants. Dealing with potential differences in the status of social work - and expectations in a new jurisdiction about one's professional status as a social worker - was also assessed by most to be not particularly challenging, as the median response was 2 on the 5-point scale. For each of the other four elements, the median response was the middle response - halfway between Not at all challenging and Completely challenging. The greatest proportion of participants who found any of the elements completely challenging was $13 \%$ - in other words, one out of every eight participants found adjusting to the work culture completely challenging. 


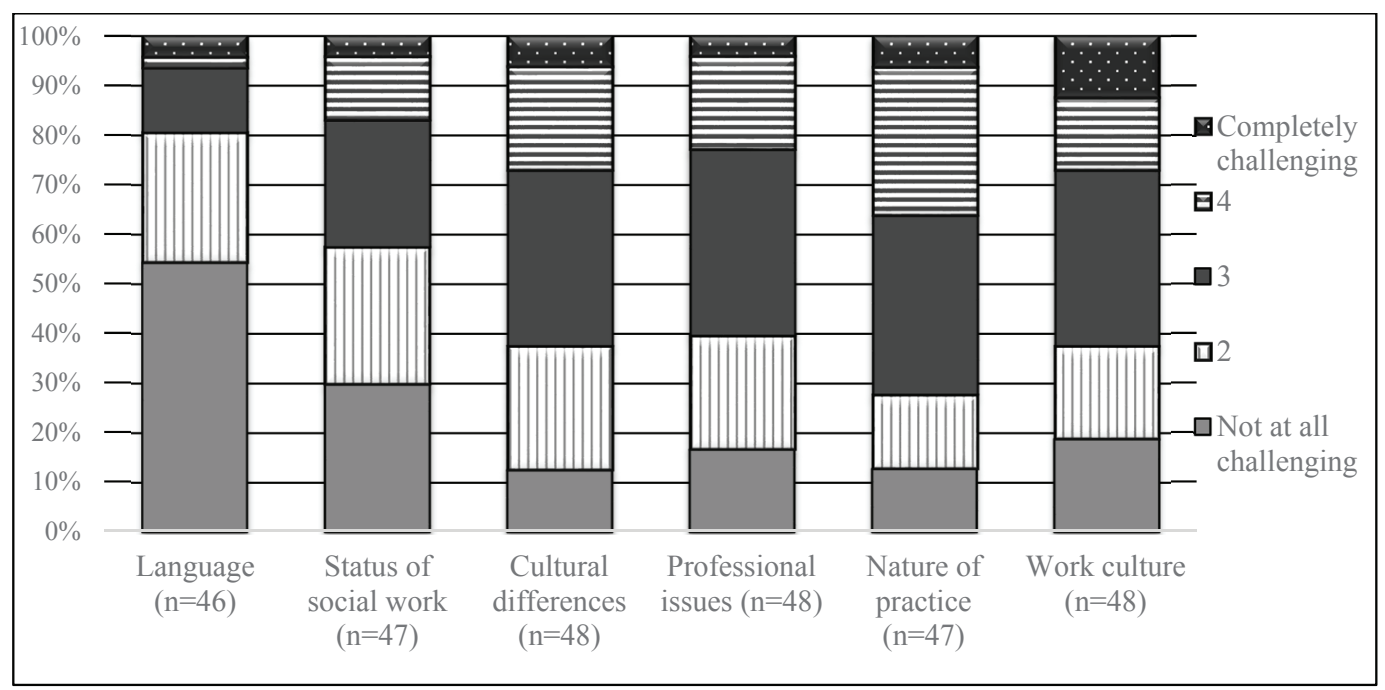

Figure 4. Challenging elements in practising as a social worker overseas.

Participants were also given a response option of Other, and were able to specify additional elements that they had found challenging in practising as a transnational social worker, and six participants did so. Four of these six participants indicated that these other elements were Completely challenging. Most of the elements these participants identified were related to the organisational aspects of the work. These included:

- $\quad$ adjusting to working in large cities;

- $\quad$ racism by non-social work colleagues in multi-disciplinary teams;

- Very heavy caseloads and 'overwhelming accountability requirements';

- Very high incidence of workplace bullying.

Two participants highlighted challenging elements involved in working in very different contexts. One of these highlighted child trafficking and honour killings; the other merely stated, "The most challenging work environment was South Africa - all aspects of work there were completely challenging."

\section{Comparisons}

When asked to reflect on the similarities and differences in practice between Aotearoa New Zealand and the overseas country of their most recent practice experience, between 40 and 43 participants responded to the range of elements compared, shown in Table 5. Responses varied considerably across each element, which is not surprising, given the range of countries in which these professionals were practising. The elements that were deemed most similar to the Aotearoa New Zealand context across the sample were the complexity of family work, particular social issues and relationships of accountability. Those elements deemed to be most different from the Aotearoa New Zealand context were those dealing with administrative or procedural components of the job: computer systems and forms, paperwork and bureaucracy. Responses to the item 'status of the role of social worker' were reasonably evenly spread across all four categories, ranging from 'very similar' to 'very different'.

\section{Open question findings: Overseas experience reflections and comparisons}

The open questions provided the opportunity for participants to comment briefly in their own words about the benefits and challenges 
Table 5. Similarities and Differences in Practice (Compared to Aotearoa New Zealand)

\begin{tabular}{|c|c|c|c|c|}
\hline & Very similar & A bit similar & A bit different & Very different \\
\hline Complexity of family work $(n=40)$ & 47.5 & 22.5 & 22.5 & 7.5 \\
\hline $\begin{array}{l}\text { Particular social issues (domestic violence, } \\
\text { substance abuse, etc.) }(n=43)\end{array}$ & 48.8 & 20.9 & 20.9 & 9.3 \\
\hline Relationships of accountability ( $n=42$ ) & 19.0 & 33.3 & 28.6 & 19.0 \\
\hline Professional autonomy/decision-making $(n=43)$ & 27.9 & 11.6 & 37.2 & 23.3 \\
\hline Status of the role of social worker $(n=43)$ & 20.9 & 23.3 & 23.3 & 32.6 \\
\hline Forms/paperwork/bureaucracy $(n=43)$ & 25.6 & 16.3 & 25.6 & 32.6 \\
\hline Computer systems $(n=40)$ & 12.5 & 15.0 & 30.0 & 42.5 \\
\hline
\end{tabular}

of their overseas experience and further comparisons made on returning to Aotearoa New Zealand. We asked for comment on what participants felt were the best aspects of practising social work overseas. Frequently occurring themes in these open responses were that social work was more respected than at home; provided professional opportunities, especially for learning and development; had better pay and conditions, and professional practices and workplace culture that were deemed very robust. One participant described this latter point thus: "the professional culture was a breath of fresh air." The belief that practice was stronger in other jurisdictions had also been emphasised by participants in our study of Aotearoa New Zealand social workers practising in the United Kingdom and Ireland (Beddoe \& Fouché, 2014). Participants emphasised the advantages gained in the variety of practice and/or the ability to specialise. Sample comments include:

A more generic caseload and the opportunities for learning.

It was much more generic ... I had child abuse clients, young offenders, older adults and mental health.

Ability to specialise in different fields i.e., Working with trafficked children, immigration, homelessness for example.

Experience, seeing different models / systems of practice, cutting edge innovation in therapeutic practice.
Experiencing the differences in social work with child abuse and neglect.

I only worked in London in child protection and found the focus to be solely on the child and outcomes guided by research and evidence-based practice. This is not the case in NZ.

I was able to be part of an innovative client-centred project and the resources available for training, ongoing professional development, supervision plus direct services for clients were wonderful.

It's so good for expanding knowledge. I love change and overseas practice forces you to learn quickly.

\section{Respect}

In their open comments, participants commonly reported having felt that social work was more highly respected and better rewarded in the setting of their overseas experience in comparison to Aotearoa New Zealand, echoing our earlier findings. Respect was linked to perceptions of greater professional autonomy sitting within systems that participants felt were stronger. Noted were "[excellent] practice models, greater accountability, process, and good management structure and a better court system" especially by those who had practised in children's services. The following comments reflect these themes: 
Respect from other statutory agencies, particularly working alongside the police.

More respect shown to front line workers where I worked in the UK.

I felt that I was respected in my work with looked after children and felt that I could bring a different perspective to connecting young people with their families that they had been separated from which provided them with a sense of belonging.

Much more professional, family focused and thorough assessment with comprehensive intervention plans tailored to each individual family member.

Social workers are paid the same as psychologists and are recognised as a key part of the multi-disciplinary therapeutic team.

As a social worker I was valued and respected by my employers, colleagues and stakeholders.

\section{Stronger practice systems}

Echoing earlier comments, the participants report stronger management systems, workplace cultures and accountability, especially in the UK:

Child protection procedures are the most obvious one as they keep social work practise thresholds in line with messages from research. Caseloads are protected in front line services.

There is meaningful multi-agency decision making and most of all, social services are audited by an independent body.

Working together with all government departments and working collaboratively rather than saying we do.

I appreciated the ongoing accountability and transparency of social work practice in UK and the superior training of my colleagues.

Excellent supervision. Financial reward. Colleagues with a good work ethic.

Very little back stabbing, respected for airing your views and listened to for making positive changes in the work environment.

Exposure to different professional and organisational cultures made for negative comparisons. A critical view of available social work resources back at home in Aotearoa New Zealand featured prominently, along with negative aspects of organisational culture:

I must spend about $80 \%$ of my working week in front of the computer. There are so many assessments instead of having 1 working document which would serve the need. The computer is outdated, unfriendly and cumbersome. CYF is built on who you know - not what you know!!

I now work in a polytechnic where resources are scarce and salaries are very low. Social work seems to have become more and more bureaucratic with the community sector captured by the demands of eligibility for government funding.

We need to stop working in silos and being so protective over our agencies and work collaboratively to support the needs of our families.

We need to walk the talk when relating to colleagues as there is far too much coercion and bullying within organisations

I feel we are a bit of a backwater here in NZ in terms of practice, training opportunities, innovation.

Participants reported a stronger support for professional development with greater opportunities than in Aotearoa New 
Zealand, with one commenting, "for example I was able to lecture in Queensland without a PhD." Exposure to opportunities to develop greater cultural competence though contact with very different cultural groups and contexts was also highlighted as a strength of overseas practice, and reinforced many participants' stated motivation for choosing the transnational experience in the first place:

Exposure to a completely different context and culture. Learning how to practice social work in a completely different paradigm.

Learning to work with different cultures... loved it. Friendships made - long lasting.

Multi-cultural environments; Truer family participation in decision making processes in adult services.

Going to new places; seeing new things.

\section{The greatest challenges of working overseas}

Participants were asked to reflect on the challenges they encountered in overseas practice contexts, and they most frequently used expressions related to the challenges of working across cultures and learning about different practice and legislative expectations. The new environment often meant being exposed to unfamiliar concerns such as working with trafficked clients, female genital mutilation and children who had been ritually abused. Organisational differences and variable induction experiences echoed findings in earlier research in other settings:

Picking up new skills: Getting up to speed on legislation, learning new computer systems and processes. Learning the new procedures and ways of working which took about six months.

Lack of induction/training.

Working alone, very rarely did you go out with a colleague.
[I wanted] cultural supervision but found this difficult to obtain.

Some "low-level racism" was exercised including discrimination against $\mathrm{New}$ Zealanders. Those who had practised in Ireland noted "a challenge in Ireland understanding the accent," while another was "teased in Ireland about my accent."

Practical considerations of place included "Finding my way around the area"; "getting around [the local authority] area.... until GPS came on board"; "travelling at night was a bit scary particularly in areas around London"; costs and finding accommodation were also mentioned as everyday living challenges.

\section{The challenges of returning home to Aotearoa New Zealand}

There were many challenges reported in the return home which were largely based on the positive appraisals of the overseas experiences noted above. Concerns coalesced around disappointment with the formal organisation of social work, the lack of respect for the profession and what was described as lower professional standards, especially in statutory social work:

Feel safe that I have not returned to practise statutory child and family work in NZ as it's too dangerous - for the child and professionally for the social worker.

I have been really saddened by the "deprofessionalisation" of social work that I have experienced on my return to NZ.

Social work was more professional than here - in my experience [back in New Zealand], most statutory social workers don't answer emails and ignore telephone messages.

I have come across some extremely poor practice $\ldots$ at-risk children are left in homes too long or moved to inappropriate placements where they suffer further damage from neglect and emotional abuse. 
One participant urged care returning to work in child protection: "Be very strong about the amount of work you accept if working for $\mathrm{CYF}^{1}$ and stand up for yourself." Also, "don't come if you want to work in child protection." Another noted:

I am passionate about child protection and wanted to work in this field in NZ as I feel I have a lot to offer with my experience overseas. However, I have been horrified by the very poor practi[c] e in [statutory social work]. [For example] the social workers don't know their clients or families, there are no chronologies, there are no assessments that contain clear analysis of the issues, no risk assessments or plan[s] of action. The service provided to children in care is very worrying. I have not met a social worker yet who can tell me where a child on their case load has lived, why they moved, what the outcome of allegations of abuse are.

While one participant exclaimed "There's no place like home!!", an overall theme was that returning home is a challenging experience for which preparation is needed. Advice for social workers coming back to practise from overseas included:

Be prepared to be challenged especially if you had a positive experience of working overseas.

Returning home is tough.

Prepare yourself to feel a little disgruntled by what you return to....

Be prepared for a drop-in income. The change in pace and pay packet can make the first couple of years very difficult.

There are no salary sacrificing options in NZ. This option available in Australia meant that NGOs could provide a salary that was comparable with State Government salaries and should be considered by NZ Government ("Dreams are Free" ${ }^{\prime \prime}$.
Having returned to practise in New Zealand, more than three-quarters of the participants $(78 \%)$ had registered with the SWRB. Those returning home were advised strongly to ensure they had secured employment before returning, and to confirm the required criteria to be registered with SWRB, as recognition arrangements were identified as a frustration.

I was registered in both England and Scotland; I feel there should be some sort of recognition of this. Quite tiresome to rethink about having to do registration all over again and the time factor with the workload here in this country leaves one exhausted.

I believe ANZASW and the Social Workers Registration Board perhaps need to consider whether Kiwis in Australia are able to keep the practising certificates up to date...my work included more work with Māori and Pacific Islanders than in NZ and I had a Māori supervisor therefore I could have easily satisfied the criteria for $\mathrm{S} 2$ of Competency requirements.

Participants were asked “Do you have any additional general observations about social work in New Zealand since returning?" Common comments reflected on cultural aspects:

Biculturalism is a myth. Monoculturalism reigns supreme.

Māori over-representation is rife and this is not being addressed at a driver level. Māori families still do not have a voice in social work.

[Despite challenges], it's delightful to be back amongst people with a commitment to the Treaty of Waitangi.

When participants were asked whether they would consider working overseas again responses were largely positive, including several participants who continue to feel the pull of the overseas experience: 
I am interested in other cultures and travelling. I am interested in living overseas and see social work as a means to do so.

[I] absolutely loved working in the UK and have really struggled coming back to NZ social work.

New Zealand is very monocultural... aspects of social work in New Zealand are not being developed by way of newer research i.e. Indigenous research. Practice \& policy largely applies a "one size fits all" approach which is not working for its [principal] users, Māori!

I have thought about Australia and have made enquiries with good feedback on employment opportunities available to me.

Only one participant offered a rationale for wanting to remain in Aotearoa New Zealand: ironically, it involved being able to contribute to the local profession the knowledge and skills acquired in overseas practice:

I love NZ and have my own private practice where I can impart my overseas knowledge and experience with others to improve practice.

Finally, social justice and political action in social work were the focus of some comments by participants, several of whom shared a concern that social work needed to be more politically active and aware:

Social work in the UK is much more political and this is a major strength and something that is lacking in NZ.

We need to pull the proverbial socks up to focus on social change.

Social workers need to grow a social conscience, challenge on social issues, do not ever just accept the status quo...or we will have lost sight of what social work is about!

Social workers in statutory social work are muzzled by the government and have no voice. We do not speak out about the lack of resources for the children and young people in NZ and we do not advocate strongly for them. We have a duty of care to children and young people which we are not able to meet and we are silent. Social work is more vocal in the UK and Ireland.

\section{Discussion}

This is a small study with limited generalisability. The survey was conducted amongst members of the ANZASW, rather than the entire social work cohort in Aotearoa New Zealand - primarily because there is no way to access that population in the absence of mandatory registration. The level of churn across the social work labour markets of the Anglophone world suggests, at least, it is safe to assume that there are many more returning transnational social workers practising in Aotearoa New Zealand than the 48 who completed this exploratory study. Given the recent government announcement of a 30\% wage increase for social workers employed in Oranga Tamariki, and the widespread assertion that this must create a knock-on impact for practitioners working in the NGO and community sectors as well, it is possible to imagine that more Aotearoa New Zealandqualified social workers may consider the return home.

In general, social workers in the study had appreciated the benefits of their overseas experience. It had broadened their skills, exposed them to new systems and learning opportunities. The positive features of overseas experience were consistent, most seemed to value it immensely and appreciate the advantages, opportunities to develop and expand knowledge and skills, and to escape the "backwater."

Many commented on the strong professional cultures of social work contexts overseas, especially in children's services in the United Kingdom and Ireland, themes that have been reported (Beddoe \& Fouché, 2014; Fouché, Beddoe, Bartley, \& de Haan, 2013). These experiences also, for some, led to their being 
more critical of Aotearoa New Zealand social work, with comments as noted earlier about poor practice, lower professional status and salary, being not respected, feeling that Aotearoa New Zealand social work needs to "up its game" and did not measure up to the overseas jurisdictions in which they had practised. These comments align with the perceptions of overseas social workers in Aotearoa New Zealand as reported in our earlier research.

We have elsewhere referred to professional dislocation - a "profound, lasting sense of unease linked to disjuncture between the practice environment on the one hand, and their perceptions of the status of the profession and their own professional identity" (Fouché, Beddoe, Bartley, \& de Haan, 2013, p. 2006). In its original context, it was used to describe the experiences of transnational social workers as they left their familiar practice domains and entered the field in a new cultural context. It seems as though many of the survey participants in this current study overcame initial experiences of dislocation when they left Aotearoa New Zealand to practise overseas - sufficient for most to rate their experience as Completely satisfactory, as in Figure 3-only to experience a second form of professional dislocation on their return home.

As we have argued elsewhere (Bartley \& Beddoe, 2018; Fouché, Beddoe, Bartley, \& de Haan, 2013; Peter et al., 2017) and wish to emphasise again here this professional dislocation could be ameliorated if the responsibility to induct transnational social workers into local practice was shared by the professional bodies, rather than leaving it in the hands of individual employers, as is the current situation. To this end we are currently analysing data from a further stage of the research programme with a very specific focus on induction and engagement of incoming overseas social workers. We suggest that it may be necessary for the professional bodies (the ANZASW, as well as the statutory registration authority) to consider providing advice and support for returning professionals as well, to encourage a smoother re-entry and a more positive, productive contribution by returnees of the expert knowledge and skills they have acquired during their time abroad.

\section{Conclusion}

As reported in the growing literature on this topic, transnational mobility of social workers increasingly provides for both in- and out-bound movements of social workers. Previous research (Beddoe \& Fouché, 2014) found that Aotearoa New Zealand social workers enjoyed the opportunities of short- or long-term social work employment overseas, while acknowledging the challenges. Adjustment to new practice locations and, as shown in the small exploratory study reported here, adjustment to returning home may include negative perceptions which are disruptive to professional perspectives. While overseas practice is enriching, it carries with it both relocation benefits and costs. Employer recognition of the challenges of returning social workers, and the enhanced skills they bring home may offset some of the dislocation experienced, as may the more active involvement of the professional bodies to which practitioners belong.

\section{Note}

${ }^{1} \mathrm{CYF}$ and CYFS are both acronyms for the national statutory service responsible for child protection and youth justice services in Aotearoa New Zealand: The Department of Child, Youth and Family Services. In 2017 the service was renamed Oranga Tamariki: The Ministry for Children.

\section{References}

Ballou, J. (2008). "Open-ended questions. In P. J. Lavrakas (Ed.), Encyclopedia of survey research methods (pp. 547-549). Thousand oaks, CA: Sage Retrieved from http://methods.sagepub.com/ reference/encyclopedia-of-survey-research-methods. doi:10.4135/9781412963947

Bartley, A., Beddoe, L., Duke, J., Fouché, C., Harington, P. R. J., \& Shah, R. (2011). Crossing borders: Key features of migrant social workers in New Zealand. Aotearoa New Zealand Social Work, 23(3), 16-30.

Bartley, A., Beddoe, L., Fouché, C. B., \& Harington, P. (2012). Transnational social workers: Making the profession a 
transnational professional space. International Journal of Population Research. doi:10.1155/2012/527510

Bartley, A., \& Beddoe, L. (Eds.). (2018). Transnational social work: Challenges and opportunities of a global profession. Bristol, UK: Policy Press.

Beddoe, L., \& Fouché, C. B. (2014). "Kiwis on the move": New Zealand social workers' experience of practising abroad. British Journal of Social Work, 44(suppl 1), i193-i208. doi:10.1093/bjsw/bcu049

Beddoe, L., Fouché, C., Bartley, A., \& Harington, P. (2011). Migrant social workers' experience in New Zealand: Education and supervision issues. Social Work Education, 31(8), 1012-1031. doi:10.1080/02615479.2011.633600

Bolzman, C. (2015). Immigrant social workers and transnational practices: The example of Latin Americans in Switzerland. Journal of Immigrant \& Refugee Studies, 1-21. doi:10.1080/15562948.2015.1063745

Brown, M., Sansfaçon, A. P., Éthier, S., \& Fulton, A. (2014). A complicated welcome: Social workers navigate policy, organizational contexts and socio-cultural dynamics following migration to Canada. International Journal of Social Science Studies, 3(1), 58-68.

Fouché, C., Beddoe, L., Bartley, A., \& de Haan, I. (2013). Enduring professional dislocation: Migrant socia workers' perceptions of their professional roles. British Journal of Social Work, 44(7), 2004-2022. doi:10.1093/bjsw/bct054

Fouché, C., Beddoe, L., Bartley, A., \& Brenton, N. (2013). Strengths and struggles: Overseas qualified social workers' experiences in Aotearoa New Zealand. Australian Social Work, 67(4), 551-566. doi:10.1080/0312407x.2013.783604

Fouché, C., Beddoe, L., Bartley, A., \& Parkes, E. (2015). Are we ready for them? Overseas-qualified social workers' professional cultural transition. European Journal of Social Work, 19(1), 106-119. doi:10.1080/13691457.2015.1022858

Fulton, A. E., Pullen Sansfaçon, A., Brown, M., Éthier, S., \& Graham, J. R. (2016). Migrant social workers, foreign credential recognition and securing employment in Canada: A qualitative analysis of pre-employment experiences. Canadian Social Work Review/Revue Canadienne de Service Social, 33(1), 65-86.

Hanna, S., \& Lyons, K. (2014). Challenges facing international social workers: English managers' perceptions. International Social Work, 59(6), 722-733. doi:10.1177/0020872814537851

Harrison, G. (2013). "Oh, you've got such a strong accent”: Language identity intersecting with professional identity in the human services in Australia. International Migration, 51(5), 192-204. doi:10.1111/imig.12005

Hatzidimitriadou, E., \& Psoinos, M. (2017). A qualitative analysis of migrant social workers' work experiences and perceived prejudice from an empowering acculturative integration approach. European Journal of Social Work, 1-13. doi:10.1080/13691457.2017.1366299

Hussein, S. (2014). Hierarchical challenges to transnational social workers' mobility: The United Kingdom as a destination within an expanding European Union. British Journal of Social Work, 44(suppl 1), i174-i192. doi:10.1093/bjsw/bcu050

Hussein, S., Manthorpe, J., \& Stevens, M. (2011). The experiences of migrant social work and social care practitioners in the UK: Findings from an online survey. European Journal of Social Work, 14(4), 479-496. doi:1 $0.1080 / 13691457.2010 .513962$

Lin, C.-H., Chiang, P. P., Lux, E. A., \& Lin, H.-F. (2018). Immigrant social worker practice: An ecological perspective on strengths and challenges. Children and Youth Services Review. doi:https://doi.org/10.1016/j. childyouth.2018.02.020

Mangena, C., \& Warria, A. (2017). The challenges experienced by Zimbabwean social workers practising in Gauteng townships. Social Work/Maatskaplike Werk, 53(2), 250-265.

Modderman, C., Threlkeld, G., \& McPherson, L. (2017). Transnational social workers in statutory child welfare: A scoping review. Children and Youth Services Review, 81, 21-28. doi:https://doi.org/10.1016/j childyouth.2017.07.022

Moriarty, J., Hussein, S., Manthorpe, J., \& Stevens, M. (2012). International social workers in England: Factors influencing supply and demand. International Social Work, 55(2), 169-184. doi:10.1177/0020872811417473

Papadopoulos, A. (2017). Migrating qualifications: The ethics of recognition. The British Journal of Social Work, 47(1), 219-237. doi:10.1093/bjsw/bcw038

Papadopoulos, A. (2018). Recognising transnational social workers in Australia. In A. Bartley \& L. Beddoe (Eds.), Transnational social work: Challenges and opportunities of a global profession (pp. 223-240). Bristol, UK: Policy Press.

Peter, S., Bartley, A., \& Beddoe, L. (2017). Transnational social workers' transition into receiving countries: What lessons can be learned from nursing and teaching? European Journal of Social Work, 22(1), 16-29. doi:10.1 080/13691457.2017.1366430

Pullen Sansfaçon, A., Brown, M., Graham, J., \& Dumais Michaud, A.-A. (2013). Adaptation and acculturation: Experiences of internationally educated social workers. Journal of International Migration and Integration, 15(2), 317-330. doi:10.1007/s12134-013-0288-2

Tinarwo, M. T. (2015). Discrimination as experienced by overseas social workers employed within the British welfare state. International Social Work, 60(3), 707-719. doi:10.1177/0020872814562480

Walsh, T., Wilson, G., \& O'Connor, E. (2010). Local, European and global: An exploration of migration patterns of social workers into Ireland. British Journal of Social Work, 40(6), 1978-1995. doi:10.1093/bjsw/ bcp 141

Walsh-Tapiata, W., Simmons, H., Meo-Sewabu, L., \& Umugwaneza, A. (2018). Pōwhiri: A safe space of cultural encounter to assist transnational social workers in the profession in Aotearoa New Zealand. In A. Bartley \& L. Beddoe (Eds.), Transnational social work: Challenges and opportunities of a global profession (pp. 155-170). Bristol, UK: Policy Press.

Zanca, R., \& Misca, G. (2016). Filling the gap? Romanian social workers' "migration" into the UK. Revista de Asistenţă Socială, (1), 41-47.

Zubrzycki, J., Thomson, L., \& Trevithick, P. (2008). International recruitment in child protection: The experiences of workers in the Australian Capital Territory. Communities, Families and Children Australia, 3(2), 30-38. 